\title{
China e sudeste asiático: diferenças e semelhanças de percepção quanto a questões atuais
}

\author{
PAULO A. PEREIRA PINTO*
}

A maioria dos países do Sudeste Asiático compartilha de passado que os inseriu, em maior ou menor escala, em esfera de influência de duas grandes civilizações: a chinesa e a indiana, que interagiram, através dos séculos, com culturas locais. O Budismo, o Islã, o Hinduismo e o Confucionismo deixaram, assim, marcas profundas que continuam a diferenciar ou aproximar pessoas.

A este mosáico de heranças culturais seculares, somou-se, mais recentemente, o colonialismo europeu que impôs, pela força, novos valores e normas de organização e comportamento. A partir do término da Segunda Grande Guerra, os Estados recém-independentes da região foram divididos, pela rivalidade ideológica das superpotências, entre os que serviriam como a vitrine da economia de mercado e os que seguiríam o sistema de planejamento centralmente planificado.

Com a multipolaridade resultante do término da Guerra Fria, ocorre o recuo das esferas de domínio de Washington e Moscou. Como conseqüência, no Sudeste Asiático, torna-se possível o ressurgimento de influências políticoculturais antigas, como a chinesa. Hoje, quando se discutem os efeitos da presença avassaladora da cultura de massa, resultante da globalização, os países da área buscam, a nível regional, marcos de referência que permitam afirmar valores, idéias e crenças, consolidadas através de uma história compartilhada numa geografia determinada.

Tal processo é facilitado pela existência, ao Sul da China, de uma rede de indivíduos com origem étnica comum, chamados “chineses de ultramar”, que têm como referência uma mesma identidade cultural.

Rev. Bras. Polít. Int. 40 (2): 144-165 [1997]

* Diplomata. Coordenador da primeira missão acadêmica brasileira à Ásia-Pacífico, em setembro de 1994. 
Este estudo parte, portanto, da premissa de que existe, no Sudeste Asiático, a influência contemporânea de um conjunto de normas estabelecidas por tradição e processo histórico chineses, sobre o universo de valores que são fatores de agregação e mesmo de progresso em países vinculados historicamente ao Império do Centro.

Isto porque, até meados do século XIX, quando se iniciou a interferência européia no Extremo-Oriente, a China desempenhou papel político dominante, bem como foi o centro radiante de civilização no Sudeste Asiático, em virtude de seu desenvolvimento cultural e sofisticada capacidade de governança. Por isso, os países do Sudeste Asiático eram mais ou menos atraídos à esfera de influência chinesa, em busca de fonte de inspiração e legitimidade política. O Império chinês reciprocava, atribuindo vínculos especiais a seus vizinhos austrais.

Tais desenvolvimentos ocorriam sem que se procurasse o domínio econômico ou a conquista territorial dos Estados vizinhos, com o emprego da força - à exceção do Vietnã -, propiciando, no Sudeste Asiático, a percepção constante da existência de uma potência regional a ser levada em conta, mas não permanentemente temida.

A Ásia-Pacífico ${ }^{1}$ vive, hoje, apesar da recente crise financeira de alguns países da área, momento de prosperidade sem precedentes, a ponto de já se ter tornado lugar comum dizer que se está prestes a entrar em nova Era, ditada pelo pólo de crescimento situado naquele oceano.

Esse processo tem incluído articulações complexas, que incluem dinâmicas regionais e externas, com conexões entre economias, setores financeiros, vínculos culturais históricos e sistemas de valores.

A vertente da cooperação produtiva, associada à fluidez do capital financeiro internacional é mais facilmente identificada e, portanto, apontada como a força motora que impulsiona essa evolução, que, até recentemente, era baseada em divisão do trabalho com forte componente vertical e dependência tecnológica excessiva do Japão.

A regionalização da produção evoluiu, no entanto, na medida em que a interação de novas tendências, entre as quais a redução nos custos da mobilidade dos fatores de produção e as economias de escala exigidas por processos produtivos crescentemente sofisticados, proporcionaram o surgimento dos chamados "tigres" ou "novas economias industrializadas". Os efeitos de tais reajustes são evidentes no aparecimento de formas de relacionamento inovadoras, que incluem diferentes tipos de parcerias entre Japão, novas economias industrializadas, ASEAN e partes da China. 
Menos nítido é o contorno político que virá a traçar o perfil do Século do Pacífico, como resultado tanto das transformações por que passa o Estado, quanto da revolução na geometria regional de poder pós-Guerra-Fria. Sabe-se apenas que, nessa fase auspiciosa, novas modalidades de participação e paz precisam ser criadas, de forma a garantir a todos os frutos do sucesso obtido, bem como para evitar a reconstrução de estruturas de confrontação, nos moldes das existentes durante a fase de bipolaridade mundial.

Verifica-se, a propósito, que o atual quadro de multipolaridade registra, por um lado, extenso leque de alterações que deverão ocorrer na ordem política daquela vasta região, necessárias a sua estabilidade. Emerge, por outro lado, conjunto de temas que, seja por dinâmica provocada pelo fenômeno de crescimento acelerado, seja por imposição de potências situadas fora da área, levam os asiáticos a criarem uma agenda própria de preocupações e um novo método de relacionamento.

Nota-se, nessa perspectiva, que, com a falência do quadro internacional de confrontação leste-oeste, prevalecente desde o término da Segunda Grande Guerra, surgiram, por um lado, diferenças e semelhanças de percepções quanto a ameaças - antigas e novas - à segurança e estabilidade na Ásia-Pacífico.

Por outro, conforme explicado por Manuel Castells, por ocasião de seminário em Brasília intitulado “O Brasil e as Tendências Econômicas e Políticas Contemporâneas” ${ }^{2}$, no momento em que a economia mundial é regida por fluxos financeiros, tecnológicos e comerciais canalizados por "redes independentes", adquire importância fundamental a conexão direta - ou rede - representada pelos crescentes vínculos econômicos entre a China e o Sudeste Asiático.

Isto é, no que diz respeito às questões de segurança, durante a fase de bipolaridade mundial, tratava-se, principalmente, de conter o perigo do expansionismo de uma das superpotências, dependendo da opção ideológica que cada capital houvesse feito. Para tanto, criou-se, entre os aliados do Ocidente, toda uma bem sucedida aliança contra Moscou, enquanto fortaleceram-se os vínculos entre a então União Soviética e sua área de influência.

A partir do colapso da URSS e do paradigma de Yalta, deixou de existir uma das fontes tradicionais, de onde deveria ser gerado o expansionismo. O que restou do comunismo, desde então, não mais seria uma linha divisória, separando inimigos. Um pragmatismo saudável, voltado para o intercâmbio econômico e desvinculado de considerações ideológicas, passou a prevalecer nas relações entre Estados. Rússia, China e Vietnã estabeleceram vínculos diplomáticos com a Coréia do Sul, enquanto a RPC e a Indonésia reestabeleceram os seus. Os EUA e o Vietnã promoveram a troca de Embaixadores.

O mesmo aparato de segurança estabelecido na Ásia-Pacífico, durante a Guerra Fria, permanece instalado, no entanto, inadequado para eliminar focos de instabilidade, que agora emergem como prioritários e demandam novas modalidades de cooperação para solucioná-los. 
Há problemas antigos, como o da península coreana, a exigir um diálogo multilateral no nordeste asiático; o do Camboja, em fase de solução sob a liderança da ONU; e o dos territórios em disputa, a exemplo das ilhas Kurilas, entre o Japão e a Rússia, as Diaoyutai/Senkaku, entre a China e o Japão, e as Nashuas/Spratlys, entre a China, Taiwan, Vietnã, Filipinas, Malásia e Brunei.

Existem, também, temas, novos, como o da corrida armamentista regional; o da proliferação de armas de destruição em massa; e o das ameaças decorrentes não de fatores militares, mas de caráter não tradicional, voltadas para setores políticos, econômicos, ideológicos e sociais - segundo o ponto-de-vista de alguns governos asiáticos.

Voltando-se aos aspectos da globalização analisados por Manuel Castells, lembra-se que ela não é una, mas múltipla ${ }^{3}$, abrangendo tanto a economia, quanto os valores e a informação, apresentando interlocutores distintos nos setores financeiro, produtivo ou de direitos humanos. O mundo passa a organizar-se não mais em pólos ou blocos alternativos, mas em redes concomitantes de cooperação, rivalidade e conflito, formando coalizões de geometria variável.

Nessa perspeciva, são fantásticas as alterações quantitativas - em termos de aumento de volume de produção - e qualitativas que a incorporação da China à Ásia-Pacífico vem produzindo. Não se trata, portanto, apenas da inclusão da RPC, como economia, àquela macro-região, mas, sim, das novas redes financeira, comercial e de valores chineses às conexões existentes no Sudeste Asiático.

Os limites impostos à extensão do trabalho não permitem dissertação mais longa sobre o leque de ameaças, antigas e novas, à estabilidade na Ásia-Pacífico. Da mesma forma, serão mencionados apenas em linhas gerais os aspectos das redes de conexão entre a RPC e os países ao Sul de suas fronteiras.

A preocupação central do estudo situa-se nas diferenças e semelhanças de percepção entre a China e os países da ASEAN, quanto a questões atuais. O autor pretende tratar o tema a partir da perspectiva de que, com respeito àquela área, existem notícias e análises quase diárias quanto ao fenômeno de crescimento econômico, política interna ou externa e modernização das forças armadas, entre outros assuntos. Ressente-se, contudo, da escassez de estudos prospectivos mais abrangentes, que levem em conta a integração de fatores culturais, políticos, econômicos e de segurança. Essa visão estratégica é a sugerida no trabalho.

Cabe assinalar que, desde o início de suas relações, até o momento em que se discutem questões atuais a China demonstra ter, com respeito aos países do Sudeste Asiático, bem como quanto a seu relacionamento com a região, percepção bem distinta da que aqueles países têm sobre si próprios e a propósito da influência chinesa em sua parte do mundo.

A China, ademais, sempre tratou de forma diferenciada cada nação situada na Nanyang (Mar do Sul da China), tendo sempre, portanto, percepção distinta sobre cada uma. Em contrapartida, a partir de sua emancipação política, os Estados 
modernos do Sudeste Asiático demonstram percepções independentes sobre aquela República Popular.

Não se pode ignorar, da mesma forma, que os atuais membros da ASEAN sempre apresentaram - e ainda o demonstram no presente - diferentes estágios de evolução política, cultural e econômica, que, com freqüência, os dividiram. Podese afirmar, no entanto, que existe um passado comum, devido ao fato de situaremse em área de influência tradicional chinesa, que leva os países do Sudeste Asiático a compartilharem pontos-de-vista sobre temas regionais que, ora conflitam, ora coincidem com a visão da China.

Na conclusão, procurar-se-á demonstrar que um ressurgimento moderno da influência cultural chinesa no Sudeste Asiático tende a ser fator de estabilidade que, gradativamente, contribuirá para superar as diferenças de percepção e consolidar as semelhanças de interesses, em benefício da estabilidade regional.

Em certa medida, é como se uma nova ética nas formas de atuação do Estado - nos moldes confucionistas - viesse, novamente, a permear as relações internacionais na região vindo a "preencher o vácuo ideológico deixado pelo colapso das grandes utopias do passado"4.

\section{III}

Conforme mencionado acima, as relações entre Pequim e as capitais do Sudeste Asiático evoluem no quadro de movimento de integração econômica regional fortemente influenciado por "redes" de natureza financeira, comercial e de valores entre os nacionais da RPC e os overseas Chinese residentes ao Sul da China.

Essa evolução será facilitada por aspectos relacionados com a existência de uma base cultural chinesa, a sustentar o modelo de desenvolvimento ora bem sucedido em um fenômeno de cross fertilization ${ }^{5}$ entre aquela área considerada historicamente como situada na periferia do Império do Centro, e a RPC, através de intercâmbio em que, por um lado, Pequim voltaria a fornecer a moldura ideológica de sustentação para a estabilidade da área e, por outro, seus já bem sucedidos vizinhos, em troca, indicariam os rumos para o aperfeiçoamento da "economia de mercado com características chinesas".

O que se pretende ressaltar, por outro lado, é o fato de que, desde o início da atual política de modernização da China, na década de $1970^{6}$, há desdobramentos que facilitam uma possível futura congruência entre a área de influência tradicional da cultura chinesa e uma nova fronteira econômica da RPC .

Tal processo de ampliação perduraria até que se obtivesse, através de um processo gradativo de building blocks, uma moldura política regional com forte influência do ordenamento histórico em que, durante séculos, parte da área hoje situada entre Myanmar e Vietnã esteve inserida em grande arco de Estados vinculados ao Império do Centro. 
Na primeira etapa dessa evolução, logo após o desaparecimento de Mao Zedong, integrou-se o próprio sistema econômico chinês. Em seguida, vieram as Áreas Econômicas Especiais, onde foram permitidas práticas de economia de mercado dentro de um sistema centralmente planificado mais amplo. A maximização de Hong Kong, em seu papel histórico de porta de contato com o resto do mundo, será o bloco posterior. Uma vez alcançada a reintegração de Taiwan, estaria completada a restauração do domínio territorial do antigo império chinês e restaria o bloco final no caminho de abertura da China, no sentido da modernização, que abrangeria os países do Sudeste Asiático com fortes contingentes populacionais de origem chinesa.

Este último desenvolvimento ocorreria através do intercâmbio de referenciais de valores entre aquela área, considerada historicamente como situada na periferia do Império do Centro, e a RPC. Assim, por um lado, a existência de uma base cultural chinesa serviria de plataforma de sustentação para um processo de cooperação com o Sudeste Asiático.

Por outro, haveria os tipos de contribuições seguintes:

- Os países bem sucedidos como a "vitrine do Capitalismo no Sudeste Asiático" - a exemplo de Cingapura - indicariam os rumos para o aperfeiçoamento da "economia socialista de mercado ${ }^{7}$ ”, com características chinesas, ora buscada pelo programa de modernização da RPC;

- A persistência do Vietnã em manter seu sistema central de planejamento, ao mesmo tempo em que adota "práticas de economia de mercado", reforçaria a proposta chinesa de manter a vertente "socialista" entre as medidas que estão sendo testadas, no programa de modernização da República Popular da China; e

- O esforço de composição permanente, no sentido da manutenção da harmonia e convivência pacífica entre a população de origem chinesa e os de fé islâmica, na Malásia e Indonésia, serviria como inspiração para exercício semelhante a ser promovido na região central da RPC, principalmente na província de Xinjiang, onde há expressivo contingente de muçulmanos, bem como a necessidade de relacionar-se com novas Repúblicas, como a do Tadjiquistão, onde predomina a mesma religião.

Assim, ressalta-se o exemplo emblemático de Cingapura que possui, hoje, pelas razões históricas expostas no trabalho, um relacionamento privilegiado com Pequim. Em resumo, recorda-se que, na península malásia, existe a maior comunidade de overseas Chinese e que o equilíbrio racial e a segurança da área tem dependido do exercício de busca constante de estabilidade regional, em suas relações com a RPC. Em Cingapura, é de 75\% a participação de chineses na população de cerca de 3 milhões. Na Malásia, aquele grupo étnico corresponde a cerca de 35\% do total de 17 milhões de habitantes. Cingapura chega a ser chamada 
de a “Terceira China” - em seguida à RPC e Taiwan. Na Malásia, onde os chineses concentram parcela desproporcional da riqueza do país em suas mãos, o Governo teme que aquela minoria possa vir a representar um futuro “cavalo de Tróia”, caso não seja possível promover sua maior integração na sociedade como um todo.

As relações econômicas entre a China e a Malásia têm apresentado perfil distinto das desenvolvidas com os demais membros da ASEAN. Desde a fundação da RPC, o volume, composição e estabilidade do comércio chinês com a península malásia têm servido de esteio para as transações com a região do Sudeste Asiático. Houve momentos em que o intercâmbio da China com a área reduziu-se virtualmente à Malásia e à Cingapura, em virtude de boicote internacional ou em razão de turbulência interna chinesa. Como conseqüência, esses países consolidaram-se como intermediários naturais para o comércio com a República Popular, mesmo após a normalização das relações com os demais membros da ASEAN, na década de 1980.

Hoje, a moldura política existente permite estar sendo construída uma réplica daquela cidade-Estado no Nordeste da China, onde vivem cerca de 200 milhões de pessoas, com o maior poder aquisitivo e nível cultural do país. Trata-se de um novo conceito de prestação de serviços, que não inclui apenas a transferência de fábricas, em busca de custos mais baixos, mas a exportação a parte RPC de todo um modelo sócio-econômico, com padrões de consumo e necessidades de infra-estrutura, em moldes dos hoje existentes naquela capital do Sudeste Asiático. Tal processo confirma a impressão de que se está vivendo profundas transformações paradigmáticas naquela parte do mundo, na medida em que convivem o velho e o novo.

\section{IV}

O raciocínio acima não deriva, unicamente, de exercer o gosto oriental por processos cíclicos, sempre presentes nas filosofias predominantes naquela parte do mundo.

A percepção de que está em curso a reemergência de uma pax sinica, ao Sul da China, deriva dos seguintes fatos:

- O desdobramento da atual macro-estrutura internacional tem-se refletido, no Sudeste Asiático, pelo recuo das esferas de influência prevalecentes durante o período da Guerra Fria. Como resultado, o clima de distensão generalizado e os esforços em curso no sentido da integração e cooperação econômica favorecem a busca de uma moldura política estável, que permita às nações da área concentrarem o máximo de suas atenções no desenvolvimento econômico;

- A nova multipolaridade regional, contudo, tem que levar em conta divergências históricas entre a China e os membros da ASEAN. Por um 
lado, é possível observar que a RPC tem pretensões que considera legítimas com respeito ao exercício de influência sobre o SudesteAsiático, onde prevaleceram, durante séculos, relações de vassalagem com o Império do Centro;

- Por outro, verifica-se o temor dos países do Sudeste Asiático, quanto à existência real de futura ameaça de hegemonismo chinês. Esse receio deriva de avaliação do potencial ainda inexplorado da China, bem como de sua futura capacidade de projetar o poderio militar sobre a região;

- A “Nova Ordem Internacional”, no entanto, tem apresentado preocupações mais imediatas aos países daquela área que pretendem manter sua alta taxa de crescimento. A natureza autoritária do regime de quase todos os integrantes da ASEAN (com exceção apenas das Filipinas), por exemplo, torna-os, agora, alvo de críticas dos EUA, CE e mesmo Japão, quanto a direitos humanos e garantias democráticas ${ }^{8}$; daí, a possibilidade de que, para a sustentação de seu modelo econômico bem sucedido, os países aseanistas tenham que apelar, gradativamente, para o embasamento da herança cultural chinesa;

- Em suma, para o estabelecimento de um contorno ideológico que favoreça os países do Sudeste Asiático, seja os que sempre se declararam capitalistas, seja o Vietnã, que continua a declarar-se socialista, a estrutura política atual adotada pela China é um importante parâmetro de referência. Para os adeptos do sistema de economia de mercado sob instituições fortemente autoritárias, há amplos traços a serem imitados e justificados no modelo político chinês. Os que desejam, de sua parte, sair da rigidez da centralização socialista sem, contudo, mudar o rótulo de seus regimes, também não terão problemas para citar suas fontes de inspiração.

Esse processo de cooperação significará a emergência de um novo paradigma, que incorpora mudanças na economia, transformações técnico-industriais nas formas de produzir e alterações na organização da sociedade, bem como é marcado pelo ressurgimento de hábitos e normas de comportamento antigos, que se tornam no mundo de hoje fatores de agregação e mesmo de progresso naquela área.

Entre esses valores, são identificados: a disciplina social; a ênfase na participação comunitária; a importância do relacionamento pessoal; o caráter prioritário da educação; a expectativa de liderança governamental; a aversão ao individualismo; a perspectiva de longo prazo; a propensão a evitar conflitos legais; a preocupação constante com a harmonia; a unidade familiar; e o sentido do dever.

Historicamente, a influência criada pela China era expressa pela sua incontestável superioridade em termos de organização política e social e produção de normas éticas de procedimento executadas exemplarmente pelos próprios chineses, na convivência entre nações. Não se procurava o domínio econômico ou 
a conquista territorial dos Estados vizinhos, com o emprego da força. Como resultado, o Sudeste Asiático tinha a percepção constante da existência de uma potência regional a ser levada em conta, mas não permanentemente temida.

A partir do século XV, emerge uma ordem em que a China desempenhava papel dominante, bem como servia como fonte de inspiração para a organização política dos Estados situados ao Sul de suas fronteiras, que adotavam sistema político-social semelhante ao monárquico chinês. Suas economias funcionavam, também, de forma similar e, através de intenso intercâmbio comercial, eram complementares. Tal esquema foi desestruturado pelos europeus, ao dividirem entre si o continente asiático, no século passado, e rompido definitivamente após a Revolução de 1949 e o advento da Guerra Fria.

Com o início do processo de modernização da RPC, na década de 1970, e o término do período de bipolaridade mundial, na de 1990, criaram-se novas condições para o ressurgimento daquela antiga moldura político-cultural. Isto é, ressurgiram, no âmbito das relações entre a China e o Sudeste Asiático, condições para o desenvolvimento de processo de cooperação, que tenha como base de sustentação aquele conjunto de valores culturais chineses compartilhados, citados anteriormente, em oposição à expansão econômica resultante da utilização da força.

Com o recuo das esferas de hegemonia ideológica, prevalecentes no período de bipolaridade mundial, fortalece-se percepção de que está em curso o ressurgimento de uma influência político-cultural chinesa como fator de estabilidade, ao Sul da China. Assim, a estrutura política atual adotada pela China torna-se um importante parâmetro de referência, na medida em que influencia um contorno ideológico favorável aos países do Sudeste Asiático, seja os que sempre se declararam capitalistas, como os fundadores da ASEAN, seja o Vietnã, que continua a declarar-se socialista.

Nessa perspectiva, para os adeptos do sistema de economia de mercado sob instituições fortemente autoritárias, há amplos traços a serem imitados e justificados no modelo político chinês. Os que desejam, de sua parte, sair da rigidez da centralização socialista sem, contudo, mudar o rótulo de seus regimes, também não terão problemas para citar suas fontes de inspiração.

Não sendo possível avaliar as diferenças e semelhanças de percepção daqueles países sobre um grande número de questões atuais, tendo em vista os limites impostos, o estudo concentrar-se-á em dois grandes temas: o da segurança regional e o dos direitos humanos.

A segurança nacional 
No que diz respeito à segurança regional, a transição da bipolaridade para a multipolaridade mundial tem exercido impacto profundo e sem precedentes na Ásia-Pacífico. A região experimenta, no momento, dinâmica própria, com ajustamentos nas relações entre os países da área, bem como entre estes e potências externas.

No exercício de reflexão, que tanto os membros da ASEAN quanto a China ora efetuam, existem questões antigas e modernas que os preocupam e desagregam. Entre as antigas encontram-se: o esforço de modernização das forças militares de cada país, que leva ao debate sobre uma possível corrida aramentista na área; as disputas territoriais entre membros da Associação - a exemplo de Sabá - e entre alguns países e a China - como as ilhas Spratlys; e controvérsias decorrentes da migração de trabalhadores intra-ASEAN.

Na medida em que a Associação se expanda, com o ingresso do Vietnã, já efetuado, a ser seguido pelo Camboja, Laos e Myanmar haverá novos desafios a serem enfrentados, em benefício da estabilidade do Sudeste Asiático. Trata-se de problemas como: a reconciliação entre os novos membros - principalmente entre o Camboja e o Vietnã; a consolidação da coesão regional, em torno dos dez membros; e a resistência contra pressões externas nos setores econômicos e políticos.

Tais preocupações, contudo, podem transmitir a falsa idéia de que se vive, no Sudeste Asiático, expectativa de turbulência. Pelo contrário, a estabilidade política e a vitalidade econômica parecem ser a realidade naquela parte do mundo.

O desdobramento da nova macro-estrutura internacional não deixa, de qualquer forma, de colocar em questão práticas consolidadas durante quase meio século, como a dependência da proteção dos EUA, na forma do principal sustentáculo da segurança regional. Para a manutenção de uma moldura de estabilidade, nesta perspectiva, são consideradas outras fontes de sustentação, que não repliquem as estruturas de confrontação ora extintas. Buscam-se, agora, também, diferentes tipos de parcerias que levem a novas modalidades de paz.

\section{A especificidade do quadro político asiático}

Com o fenômeno recente do deslocamento do poder econômico mundial para a Bacia do Pacífico, ao redor do epicentro localizado no Japão, bem como o fortalecimento estratégico da China, começa-se a ver com naturalidade a viabilidade de cenários futuros que não dependam, inevitavelmente, de raciocínios paradigmáticos sobre o equilíbrio de poder elaborados a partir da "Paz de Westphalia”, forjada no Século XVII, ou no Tratado de Utrecht, no XVIII ${ }^{9}$.

Algumas idéias geradas, no momento, em centros de estudos estratégicos asiáticos propõem afastar-se das teorias de power politics, com suas fórmulas de dominação dos fracos pelos fortes, bem como passam a especular quanto à possibilidade de que, com sua ascensão econômica e política, a Ásia possa fazer 
valer alguns dos enunciados de seus “cinco princípios de coexistência pacífica” ou dos "dez princípios de Bandung”, onde a tônica é atribuída à criação de um "mundo pluralístico onde todos os países seriam colocados em nível de igualdade”.

Nesta perspectiva, o conceito de segurança regional que ora se discute na maioria dos Centros de Estudos Estratégicos da Ásia-Pacífico leva em conta conjunto de fatores muito mais complexos do que os existentes durante a fase da Guerra Fria, entre estes os seguintes:

A) Uma noção mais abrangente de ameaça à segurança, que inclua, não apenas o perigo de agressão militar, mas também limitações impostas nos setores econômico, científico, tecnológico, político e cultural;

B) A pluralização das fontes de ameaças, que poderiam vir a proceder não apenas das potências tradicionais, mas também de outras direções, dependendo de sua natureza ou alcance;

C) A descentralização das fontes de poder, como conseqüência do colapso da estrutura bipolar de concentração EUA-URSS, e a dispersão dos pólos políticos e econômicos através da Ásia-Pacífico, o que torna o controle da área por uma única potência extremamente difícil;

D) A tendência à multilateralização, como foro de coordenação dos fatores de segurança nacional, na medida em que, conforme mencionado no item anterior, seria impossível a uma única potência assumir a hegemonia regional. Exemplo desta evolução foi encontrado no debate estabelecido desde a primeira reunião do ASEAN-Regional-Forum, realizada em Bangkok, em meados de julho de 1994; e

E) O relaxamento de tensões, resultante da crescente interdependência entre as economias asiáticas e do visível desejo de todas as nações da área quanto a priorizar moldura de estabilidade que continue a proporcionar 0 atual ritmo de desenvolvimento ${ }^{10}$.

\section{O conceito regional de segurança}

Nesta perspectiva, o conceito regional de segurança não se resume mais a fatores como os de defesa de territórios, dissuasão militar e competição entre alianças. Eventos recentes, tais como o colapso dos regimes autoritários na Europa Oriental e a emergência de vastos blocos comerciais, no continente europeu e na América do Norte, atestam que existiriam, agora, ameaças diversificadas à estabilidade dos Estados.

Como conseqüência, os países da área passaram a associar "segurança" com a capacidade de cada nação e da região como um todo, tanto de promover o desenvolvimento econômico, quanto de resistir à agressão externa. Tal conceito foi definido como de resilience, seja no plano nacional ou regional ${ }^{11}$. 
Diante do paradigma descrito acima, são efetuados esforços no sentido da introdução de confidence building measures no Sudeste Asiático, que evitem possibilidades de conflito, bem como proporcionem canais permanentes de diálogo para a discussão intra e extra-regional sobre temas políticos, econômicos e militares.

Entre tais medidas, incluem-se as seguintes:

A) A adoção de um conceito abrangente e uniforme de segurança entre todos os países da região, de forma a garantir a inclusão proporcional de fatores políticos, econômicos, sociais, culturais e militares;

B) A consolidação e expansão da cooperação na área militar, inclusive exercícios conjuntos, intercâmbio de visitas e programas de treinamento; C) A promoção de maior transparência quanto à compra e venda de armamentos, não apenas como forma de evitar erros de percepção, como também a fim de criar melhores condições para uma política industrial militar coordenada na região; e

D) A instituição de "processos de diálogo", como o ASEAN Regional Forum que, desde sua primeira conferência, realizada em Bangkok, no final de julho de 1994, reune, a cada ano, 18 Ministros dos Negócios Estrangeiros (os sete da Associação, os de seus parceiros de diálogo EUA, CE, Canadá, Japão, Austrália, Nova Zelândia e Coréia do Sul - e os do, Laos, Papua Nova Guiné, Rússia e China).

Finalmente, verifica-se existir consciência crescente, entre os membros da ASEAN, de que, no processo de transformações ora em curso, resultante do fenômeno de crescimento econômico acelerado, a segurança de cada país depende muito dos mecanismos de que disponha para canalizar as reivindicações políticas de classes sociais emergentes.

\section{As diferenças de percepção entre a China e o Sudoeste Asiático}

Os problemas entre a China e o Sudeste Asiático têm origem histórica, que levam alguns países a acreditarem que Pequim julgaria ter direito a influenciar os acontecimentos em sua antiga área de hegemonia cultural e dependência política, conforme visto na introdução do trabalho.

Este temor foi reforçado, particularmente, pelo fato de que, após a consolidação da RPC, em 1949, e com ênfase especial na década da Revolução Cultural, Pequim ter procurado exportar seu sistema ideológico, através de apoio a movimentos de insurgência de inspiração comunista e base étnica chinesa, em diferentes países do Sudeste Asiático.

Sabe-se, a propósito, que aquela área caracteriza-se por delicado equilíbrio racial, onde, em especial na Malásia e na Indonésia, as minorias chinesas possuem 
forte poder econômico, bem como contam com intensa antipatia do grupo étnico malásio.

Nesta perspectiva, o ponto atual de confrontação entre a China e o Sudeste Asiático é o Mar do Sul da China, onde se encontram em disputa ilhas denominadas Paracels, Pratas, Macclesfiels Band e Spratlys. Além da RPC, reivindicam soberania sobre o arquipélago Vietnã, Malásia, Filipinas, Taiwan e Brunei.

Os chineses completaram a ocupação das Paracels em janeiro de 1974, após confronto com os sul-vietnamitas. Em março de 1988, foi a vez de sete ilhas do grupo das Spratlys, na sequência de batalha naval com os vietnamitas.

De acordo com artigo publicado na revista Far Eastern Economic Review, em 23.02.95, o Vietnã continua a ocupar 21 ilhas, a Malásia 3 e as Filipinas 8. Taiwan manteria a mais extensa, conhecida como Itu Abu. A Indonésia, sem aspirar a nenhum dos territórios em questão, verifica que sua zona econômica exclusiva, a partir das Natuma Islands coincide com área do mesmo tipo reivindicada pela China, criando-se, assim, conflito de interesses que deverão ser discutidos no futuro.

Nas capitais aseanistas, tem havido intenso debate sobre as intenções chinesas quanto ao referido mar meridional. A versão histórica mais corrente é a de que se trata de determinação de Pequim no sentido de demonstrar, na questão das ilhas em disputa, a mesma intransigência exibida no que diz respeito à incorporação de Hong Kong e Taiwan. Isto é, tratar-se-ía de demarcação final do território da China, através da eliminação de qualquer vestígio da ocupação das potências ocidentais, iniciada no século passado.

Outros setores de opinião identificam apenas o desejo da China de participar da exploração dos recursos energéticos, cuja existência tem sido amplamente divulgada.

Fator especial de irritação para as demais partes interessadas diz respeito à proposta chinesa de apenas discutir a exploração conjunta da referida riqueza, sem colocar em questão a soberania sobre as ilhas.

Durante sua visita a Cingapura, em agosto de 1990, o Primeiro-Ministro Li Peng sugeriu "putting aside for the time being the question of sovereignty" 12 . Observadores regionais viram, nesta declaração, a realidade de que Pequim atribuiria importância unicamente a seus projetos de desenvolvimento, em detrimento de maiores atenções quanto à prioridade concedida por seus vizinhos à discussão sobre soberania.

Em 25 de fevereiro de 1992, o Comitê Permanente do Congresso Nacional do Povo da RPC aprovou lei que, ao incorporar ao território chinês as ilhas Parcels e Spratlys, deixou pequena margem de dúvida quanto à real amplitude das negociações a que poderão almejar seus interlocutores no Sudeste Asiático.

No decorrer de 1995, o Governo filipino, preocupado com repetidas 
incursões da Marinha e de pescadores chineses em águas que, segundo a convenção sobre o Direito do Mar, estariam na zona econômica exclusiva das Filipinas, tomou providências tanto no sentido de promover conversações diretas com Pequim quanto emitiu declarações de protestos contra a iniciativa da RPC, buscando internacionalizar o problema, atraindo atenções externas.

Os filipinos procuraram, também, contrarrestar a infiltração chinesa nos mischief reefs, criando fatos consumados em seu favor, apresando barcos, capturando pescadores "invasores" e destruindo instalações e marcos chineses. Alguns arrecifes e atóis adicionais foram ocupados por militares das Filipinas e chegou-se, mesmo, a organizar uma media tour que por pouco não resultou em cruento incidente, dada a presença na área de fragatas chinesas.

A questão das Spratlys foi levada à consideração do Asean Regional Forum, durante sua reunião em Brunei, em julho de 1995. Na linha de raciocínio exposta acima, o ARF foi criado com o intuito de desempenhar papel central na formação de esquema de segurança, que venha a abranger toda a Ásia-Pacífico, a partir da experiência adquirida pela ASEAN na prevenção de conflitos no Sudeste Asiático.

\section{As semelhanças da percepção}

Entre os fatores que agregam e aproximam a China do Sudeste Asiático encontra-se a semelhança de percepção quanto à necessidade de preservar o Estado como agente capaz de fomentar o desenvolvimento do sistema político, bem como garantidor das aspirações e interesses individuais e coletivos.

Isto é, na Ásia-Pacífico, procura-se defender identidades culturais seculares e mesmo milenares das consequências do fenômeno da globalização. Busca-se, assim, a garantia de que o Estado conseguirá evitar o desaparecimento da sociedade como agregadora, com capacidade de proporcionar a unidade política, bem como gerenciar atividades ecônomicas, preservar heranças culturais e, até mesmo, o emprego tradiconal.

Conforme se verificará a seguir, existe todo um Asian way para equacionar este tipo de situação.

\section{O jeito asiático}

O interesse acadêmico sobre a evolução dos regimes políticos na ÁsiaPacífico intensificou-se, desde o término da Guerra Fria. Recentemente, novas perguntas têm sido formuladas, entre estas a que diz respeito às possibilidades de o fenômeno universal da falência do autoritarismo vir a produzir o mesmo tipo de padrões democráticos, nos termos aceitos pelo Ocidente, no continente asiático, onde experiências históricas, muitas vezes milenares, provocaram a emergência 
de formações sociais organizadas de formas bastante originais, tanto na China quanto nos países membros da ASEAN.

Na mesma perspectiva, coloca-se o debate quanto ao desenvolvimento do sistema capitalista e das práticas de economia de mercado em países de acelerado crescimento, onde personalidades fortes ou partidos políticos com longa permanência no poder, levaram o Estado a desempenhar papel preponderante no funcionamento das forças de mercado. Também neste setor são notadas marcantes diferenças entre os modelos adotados na Ásia-Pacífico e os de tradição européia e norte-americana.

Nota-se, a propósito, a crescente preocupação com o fato de que as diferenças de percepção, ora existentes, quanto às práticas democráticas e à utilização das forças de mercado poderiam vir a constituir a essência de nova divisão ideológica, entre o Extremo-Oriente e o Ocidente.

Exemplo desse tipo de confrontação é encontrado, anualmente, quando se discute, em Washington, a questão da extensão do tratamento de "nação mais favorecida” à RPC e, nessas ocasiões, são refeitas análises sobre a situação dos Direitos Humanos naquele país asiático. Tais disputas tendem a ofuscar, contudo, a permanência da clivagem fundamental do planeta entre os países ricos e pobres, no que se convencionou chamar de divisão Norte-Sul.

Novos critérios de julgamentos recentemente emitidos pelos países industrializados, com respeito aos padrões de direitos humanos e formas de organizar o mercado nos países em desenvolvimento, constituem exemplos, na verdade, de formas inovadoras de protecionismo. Isto é, ao contrário da própria teoria advogada pelas nações capitalistas, nos últimos cinquenta anos, no sentido de que deveriam prevalecer as livres forças de mercado, critica-se, agora, o aproveitamento dos baixos custos da mão-de-obra em áreas onde existe farta oferta deste fator de produção, como no Sudeste Asiático.

Conforme apontado pelo Primeiro-Ministro da Malásia, Datuk Mahathir Mohamad, existiria, no momento, esforço dos Estados Unidos para reduzir vantagens comparativas dos "tigres" asiáticos, através da imposição de níveis mais altos de "direitos trabalhistas" - significando salários nos patamares existentes no mundo industrializado ${ }^{13}$. Segundo o dirigente malásio, "quando éramos meros exploradores de seringueiras e de minas de estanho, ninguém se preocupava com nossos salários”. Seria apenas quando seus produtos começaram a evoluir na ladeira tecnológica, bem como a competir favoravelmente nos mercados do Ocidente, que os mecanismos de formação de preços na economia daquele país passaram a preocupar as capitais européias e norte-americanas.

Instituições de pesquisas situadas em membros da Associação das Nações do Sudeste Asiático, principalmente as de Cingapura e Malásia, encontram-se empenhadas na formulação de um arcabouço conceitual para justificar os valores que ora caracterizam o “jeito” asiático. Nesse exercício, a 
Professora cingapureana Chan Heng Chee, do Centro de Estudos do Sudeste Asiático, com sede naquela ilha, procura ressaltar a importância da eficiência governamental como fator de legitimidade dos dirigentes políticos ${ }^{14}$. Tal perspectiva, no entanto, não deixa espaço razoável para a criação de mecanismos apropriados que permitam a alternância de pessoas eficientes, ao mais alto nível de poder, no caso de necessidade de mudanças na administração da economia.

Seu conterrâneo e colega Tommy Koh relacionou, em recente artigo publicado no International Herald Tribune ${ }^{15}$, alguns dos traços dominantes da organização política das sociedades bem sucedidas economicamente no ExtremoOriente. Entre estes cita : um contrato social entre a população e o Estado, que garante a lei e a ordem em troca do respeito pela autoridade; o mesmo entendimento procura desenvolver a autoconfiança, sem um excesso de benefícios proporcionados pelos Estados; a preservação da moralidade pública é considerada essencial; a imprensa deve ser livre, mas responsável; acima de tudo, o individualismo excessivo do mundo ocidental deve ser rejeitado, em favor dos direitos da coletividade.

\section{A discussão de uma agenda própria na área de direitos humanos}

Sem entrar no mérito dessas questões, verifica-se que no esforço de reflexão em curso para a definição de uma agenda própria para a Ásia-Pacífico insere-se, entre outros temas, a discussão sobre suas formas originais de organização política. Trata-se de procurar valorizar tais características, a partir de um ponto-de-vista asiático, sem os preconceitos a elas associados pela perspectiva Ocidental.

Nota-se, a propósito, que não partiu da Associação a escolha de inclusão das áreas de direitos humanos e democracia na pauta de assuntos ora discutidos com seus parceiros de diálogo. Foram desenvolvimentos políticos como a truculência do Governo de Jacarta na repressão aos rebeldes no Timor Leste e as manifestações populares contra regime militar instalado em Bangkok que levaram o resto do mundo a impor o tema.

Segundo a Professora Carolina Hernandez, do Institute for Strategic and Development Studies das Filipinas, não existiria, mesmo, unanimidade de ponto-de-vista aseanista nestas áreas.

Filipinas e Tailândia desfrutariam, no momento, a seu ver, de valores democráticos na forma entendida no Ocidente ${ }^{16}$. Malásia e Cingapura, por outro lado, sofreriam limitações impostas por sistemas autoritários, que sufocariam qualquer dissidência, em benefício de uma estabilidade julgada necessária para o crescimento econômico, tido como prioritário. A Indonésia encontrar-se-ía em meio termo, sem ser uma democracia plena nem ser totalmente intransigente com a oposição ao governo - à exceção do Timor. 
Talvez pela tendência permanente da busca asiática pelo meio termo, pelo consenso em torno de pontos de interesse em comum, o Professor Jusuf Wanandi, Presidente do Center for Strategic and International Studies da Indonésia, foi o escolhido para apresentar uma posição do ASEAN-ISIS, sobre o tema, com vistas à preparação para a conferência mundial sobre direitos humanos, realizada em Viena, no mês de junho de 1993. A seguir, são expostos alguns de seus pontos principais ${ }^{17}$.

\section{A universalidade dos direitos humanos e sua indivisibilidade}

Os integrantes da Associação acreditam que os direitos humanos são universais e devem ser respeitados e promovidos em todas as suas dimensões econômica, social, cultural, civil e política - na forma reconhecida pela carta das Nações Unidas. Pela declaração dos direitos humanos e demais instrumentos internacionais. A seu ver, contudo, os direitos econômicos, sociais e culturais devem ser colocados em patamar idêntico ao dos civis e políticos.

Tal princípio, conhecido como o da indivisibilidade dos direitos, é ressaltado pelos dirigentes desta parte do mundo de forma a lembrar a seus críticos no ocidente de que, nos países industrializados, a estabilidade social e econômica já se encontra consolidada, como resultado de seu próprio estágio de desenvolvimento. É natural, portanto, segundo Jusuf Wanandi, que os direitos civis e políticos sejam priorizados na Europa e América do Norte.

Em nações ora em fase de crescimento acelerado no Sudeste Asiático, por outro lado, existe ainda todo um processo de transformação sócio-econômica, cuja moldura exige preocupação algumas vezes prioritária, em função de sua fragilidade, em relação aos direitos civis e políticos. Isto é, seria concedida atenção a estes dois últimos na medida em que os direitos sociais e econômicos estejam consolidados.

O próprio professor indonésio admite, no entanto, que possa haver alegações freqüentes de Governos Asiáticos no sentido de que, em benefício da estabilidade sócio-econômica, concessões políticas devem ser adiadas, tendo, na verdade, como objetivo, sua permanência no poder.

Em suma, haveria um denominador comum que consideraria possível que, em determinado país e momento, o desenvolvimento econômico deveria constituir prioridade em relação à implementação de um sistema democrático nos moldes ocidentais. Na medida em que o país em questão obtenha o crescimento desejado, contudo, deveria, simultaneamente, aprimorar suas instituições políticas e conceder maior participação popular nas decisões governamentais. Nesse processo, é necessário haver mecanismos de avaliação quanto à percepção dos eleitores a respeito do desempenho de seus dirigentes. 
As condições culturais específicas do Sudeste Asiático

Jasuf Wanandi ressalta, também, que, no esforço de implementação dos direitos humanos, na forma integrada mencionada acima, os estados membros da ASEAN - assim como outros em idêntico estágio de desenvolvimento - levarão em conta fatos específicos de suas respectivas culturas, tais como história, situação econômico-social, religião e evolução política.

Trata-se, nesse ponto, de opor, conforme visto daquela parte do mundo, a ênfase prioritária colocada no ocidente aos direitos individuais em relação aos da comunidade. Como se sabe, nas sociedades que sofreram influência do modelo confucionista, a coletividade tem precedência sobre o indivíduo. Segundo e esquema proposto pelo sábio chinês, deveria haver uma constante busca pela harmonia na convivência humana. Direitos individuais eram ignorados.

\section{Os princípios da cooperação, uniformização e aplicação de sanções como último recurso}

Os dirigentes da ASEAN aceitam a cooperação, incentivos e assistência de outros países e organizações internacionais, com vistas à promoção dos direitos humanos entre os membros da Associação. Tais iniciativas, contudo, devem ser tomadas através de consultas mútuas e diálogo. Deve haver cooperação, não confrontação. Não são bem aceitas, por outro lado, intervenções efetuadas por nações que, até recentemente tiveram um passado de metrópole colonial ou discriminavam contra parcela de sua própria população, por motivos étnicos.

As normas de conduta, estabelecidas como parâmetros para identificar violações de direitos humanos, deveriam ser estabelecidas por organismo internacional imparcial, que reflita valores globais compartilhados por todos Estados - e não apenas alguns - de forma a evitar que grupos restrito de potências com objetivos estratégicos mundiais estabeleçam suas próprias prioridades, no exercício de busca por dimensões específicas daqueles direitos. Acredita-se que a instituição ideal para este fim seria a já criada Comissão das Nações Unidas para Direitos Humanos.

Apenas como último recurso seriam aceitas pressões e sanções, em casos de violações grosseiras, avaliadas de acordo com critérios definidos pela comissão mencionada no parágrafo anterior. Em situações que não apresentem tal gravidade, seriam utilizados conselhos e diálogo.

\section{Conclusão}

Conforme mencionado na introdução do trabalho, na medida em que o cenário mundial se apresenta crescentemente regido por fluxos financeiros, 
tecnológicos, comerciais, culturais e de valores canalizados por "redes independentes”, adquire importância fundamental a conexão direta - ou rede representada pelo ressurgimento de vínculos históricos entre a China e o Sudeste Asiático.

Isso porque "convivem dois movimentos contraditórios no sistema internacional, um primeiro que vai na direção da globalização, impulsionado por forças centrípetas, e o segundo, que favorece a fragmentação, movido por forças centrífugas" ${ }^{\prime}$.

No que diz respeito à área da Bacia do Pacífico, objeto deste estudo, a globalização da produção representou a força motora que impulsionou a evolução de uma prosperidade sem precedentes, a ponto de já se ter tornado lugar comum dizer que se está prestes a entrar em nova Era, ditada pelo pólo de crescimento situado naquele oceano.

Tal desenvolvimento, no entanto, não isentou aquela parte do mundo da emergência de redes concomitantes de cooperação, rivalidade e conflito. Segundo a expressão de Alain Touraine, como conseqüência do movimento contraditório à globalização - o da fragmentação -, nota-se o "desaparecimento das categorias sociais, dos atores sociais em si”19. "Os indivíduos ou grupos já não se definem por seu papel nas relações sociais de produção, mas antes por suas identidades regionais, raciais, culturais ou religiosas. E o exercício dos direitos civis assegura a proliferação de novas identidades”. Ainda segundo Touraine, “em vez de nos definirmos pelo que fazemos, passamos a nos definir pelo que somos. E não apenas pelo que somos, mas também pelo que queremos, e estes desejos são muito diversos".

Verifica-se, nesse ponto, a necessidade de alguns Estados da Ásia-Pacífico de buscarem uma "relegitimação"20. Daí, conforme sugerido na introdução, o fenômeno do ressurgimento moderno da influência cultural chinesa no Sudeste Asiático, em resposta à necessidade regional de estabilidade tanto interna quanto nas relações internacionais.

Nesse processo, ressurgem, também, diferenças e semelhanças históricas de percepção quanto a problemas antigos, com conseqüências em questões atuais. Tudo isso ocorre, no entanto, no quadro das já referidas conexões diretas - ou redes - representadas pelos crescentes vínculos financeiros, comerciais, culturais e de valores, entre a China e os overseas Chinese ao Sul.

Assim, seria possível especular quanto ao movimento que estaria em curso no sentido de um ponto de congruência entre a área de influência cultural tradicional chinesa e uma nova fronteira econômica da RPC. Tal esforço de ampliação perduraria até que se obtivesse, através da gradativa justaposição de círculos concêntricos ditados por Pequim, a reemergência de ordem histórica regional em que, durante séculos, o Sudeste Asiático esteve inserido em grande arco de Estados vinculados ao Império do Centro. 
Conforme mencionado no início do trabalho, vive-se um momento de ruptura, com o deslocamento do eixo mais dinâmico da economia mundial para a Ásia-Pacífico. Verifica-se, contudo, que, enquanto parece haver certa nitidez quanto ao rumo atual do avanço tecno-econômico naquela área, não se identifica, ainda, com idêntica clareza, a evolução política que proporcionará a moldura de estabilidade regional adequada para a formação de um modelo ideológico de sustentação, que servirá de base para a continuação do progresso material e segurança.

Segundo alguns setores de opinião, no entanto, os laços culturais existentes entre a China e países situados ao Sul de suas fronteiras poderão ser fator determinante no processo de integração entre a RPC e o Sudeste Asiático.

Dezembro de 1997

\section{Notas}

1 Quando se fala em Ásia-Pacífico - como fator de dinamismo econômico - tem-se em mente o conjunto formado pelo Japão, os quatro “tigres asiáticos”- Cingapura, Coréia do Sul, Hong Kong e Taiwan, e os países da ASEAN - Brunei, Filipinas, Indonésia, Malásia, Tailândia, Vietnã e novamente Cingapura. Parcela crescente do território chinês, ao longo de sua costa do Pacífico, vem sendo incorporada a esta área geo-econômica.

“O Brasil e as Tendências Econômicas e Políticas Contamporâneas”- Seminário de Brasília, 2 e 3/12/94. FUNAG, 1995. Pag. 15.

3 Mesma referência item anterior. Intervenção do Embaixador Celso Lafer, pag. 40.

4 Texto de palestra proferida pelo Presidente Fernando Henrique Cardoso, por ocasião de sua visita ao México, em fevereiro de 1996.

5 Segundo “The Random House Dictionary of English Language, Sencond Edition Unabridged”, "cross fertilization" pode ser entendido como: "interaction or interchange, as between two or more cultures, fields of actvity or knowledge, or the like, that is mutually beneficial and productive”.

6 Entre as conquistas do processo de modernização da economia chinesa, iniciado a partir do final da década de 1970, encontram-se : o fato de que as livres forças de mercado determinam, nos dias de hoje, a formação de preços de cerca de $80 \%$ da produção agrícola e industrial; a estrutura de propriedade da economia sofreu reajustes drásticos, com o setor privado absorvendo agora mais de $60 \%$ do PNB; as empresas estatais adquiriram autonomia crescente, ao mesmo tempo em que são submetidas, cada vez mais, às demandas do mercado; o sistema de distribuição e circulação de mercadorias passou a depender menos de um centro de decisões centralmente planificado; foi concedido enorme impulso à abertura da economia ao exterior, com o fortalecimento dos vínculos econômicos, comerciais e de investimentos com o resto do mundo.

7 O conceito de "economia socialista de mercado"é, ainda, pouco preciso. Seriam características suas: a propriedade estatal de $51 \%$ dos setores estratégicos da economia, entre estes o de energia, telecomunicações, produção de armamentos, aço, etc.; um sistema de assistência social aos trabalhadores em que haveria divisão de responsabilidades entre o Governo e as Empresas - algo nos moldes existentes no Japão; o planejamento macroeconômico a longo prazo permanece responsabilidade do Governo Central, enquanto as decisões relativas às decisões empresariais, a nível micro, ficam sujeitas às forças de mercado. 
8 A Conferência das Nações Unidas sobre Direitos Humanos, realizada em Viena, em junho de 1993, foi palco de polarização entre países industrializados do Ocidente e da Ásia, com respeito às formas de governança adotadas em alguns Estados asiáticos.

9 Sobre a especificidade do quadro político asiático, refiro-me ao estudo On the Establishment of Asia-Pacific Multilateral Security Dialogue Mechanism, do "China Institute of Contemporary International Relations”, vol. 4, Nr. 2, fevereiro de 1994.

10 O “CICIR ”, instituto chinês mencionado na nota anterior, publica, também, sobre a questão de segurança na Ásia-Pacífico, entre outros, o estudo A Survey of Current Asian-Pacific Security, vol. 4, Nr. 7, julho de 1994.

11 WANANDI, Jasuf. The Indonesian Quarterly, vol. XVI, Nr. 1, 1988.

12 Far Eastern Economic Review, 23 de fevereiro de 1955, pag. 14.

13 O Primeiro-Ministro Mahathir Mohamad fez a referida declaração à revista Far Eastern Economic Review, em entrevista publicada na edição de 7 de abril de 1994, pag. 20.

14 As declarações da Prof. Chan Heng Chee, bem como a de outros teóricos da tese de um "Jeito Asiático”, são publicadas em artigo da Far Eastern Economic Review, em março de 1994, no artigo intitulado “The Asian Way”, pag. 22 e seguintes.

15 No mesmo artigo citado na nota anterior, Tommy Koh afirma que "For generations Asians have learned from the West and we continue to do so. I hope the time has come when the West should also be willing to learn from the East.”

16 Registrei estas afirmações da Prof. Carolina Hernandez durante entrevista mantida, em março de 1994, quando da preparação da vinda de Missão Acadêmica brasileira para contatos com centros de estudos estratégicos da Ásia-Pacífico.

17 WANANDI, Jasuf. Conferência intitulada "Human Rights and Democracy in the ASEAN Nations: the Next 25 Years”, publicada no ASEA-ISIS Monitor, vol. 5, outubro-dezembro de 1992.

18 LAFER, Celso e FONSECA JR, Gelson. O Papel da Integração no Novo Contexto Internacional. Questões Políticas. Introdução.

19 CARDOSO, Fernando Henrique. Conferência pronunciada pelo Presidente na Universidade de Stanford, California, EUA, em 11 de março de 1996. Pag. 7.

20 Mesma referência nota 19, parágrafo 30.

\section{Resumo}

China e Sudeste Asiático têm diferenças de percepção quanto a questões de segurança regional atuais, em virtude de experiências históricas, que levam alguns países situados ao Sul da RPC a acreditarem que Pequim poderia voltar a desempenhar papel dominante na área de sua antiga influência político-cultural. Fortalecem-se, por outro lado, as semelhanças de percepção quanto à necessidade de preservar o Estado, como agente capaz de fomentar o desenvolvimento do sistema político, bem como garantidor das aspirações e interesses individuais e coletivos.

\section{Abstract}

China and Southeast Asia, due to their historic expeirences, have different perceptions about comtemporary regional security issues that lead some countries 
located at the South of CPR to believe that Pekin could come back to play the dominant role on its ancient political and cultural influence area. On the other hand, similar perceptions about the need of preserving the State as the agent able to foment the development of the political system as well as the guarantor of individual and collective aspirations and interests have strengthned.

Palavras-chave: China: tradição, proximidade, segurança, direitos humanos. Sudeste Asiático.

Key-words: China: tradition, proximity, security, human rights. Southeast Asia. 